\title{
Chiara Molinari, Parcours d'écritures francophones. Poser sa voix dans la langue de l'autre
}

\section{Sara Vecchiato}

\section{(2) OpenEdition}

1 Journals

\section{Édition électronique}

URL : http://journals.openedition.org/studifrancesi/28388

DOI : $10.4000 /$ studifrancesi.28388

ISSN : 2421-5856

Éditeur

Rosenberg \& Sellier

\section{Édition imprimée}

Date de publication : 31 décembre 2006

Pagination : $659-660$

ISSN : 0039-2944

\section{Référence électronique}

Sara Vecchiato, «Chiara Molinari, Parcours d'écritures francophones. Poser sa voix dans la langue de l'autre ", Studi Francesi [En ligne], 150 (L | III) | 2006, mis en ligne le 30 novembre 2015, consulté le 08 novembre 2020. URL : http://journals.openedition.org/studifrancesi/28388 ; DOI : https://doi.org/ 10.4000/studifrancesi.28388

Ce document a été généré automatiquement le 8 novembre 2020.

\section{(c) $($ ) $\odot$}

Studi Francesi è distribuita con Licenza Creative Commons Attribuzione - Non commerciale - Non opere derivate 4.0 Internazionale. 


\title{
Chiara Molinari, Parcours d'écritures francophones. Poser sa voix dans la langue de l'autre
}

\author{
Sara Vecchiato
}

\section{RÉFÉRENCE}

CHIARA MOLINARI, Parcours d'écritures francophones. Poser sa voix dans la langue de l'autre, Paris, L'Harmattan, 2005, pp. 248.

1 Cette monographie analyse une des problématiques centrales des littératures francophones, à savoir la relation entre la dimension langagière et linguistique du pays d'origine de l'écrivain et celle de la France métropolitaine, qui fournit la variété de référence pour le travail d'écriture. «Poser sa voix dans la langue de l'autre» devient un acte de surconscience linguistique, qui pousse l'écrivain à exploiter des techniques stylistiques aptes à refléter la coexistence de plusieurs codes.

2 Au cœur de la problématique se situent le plurilinguisme et le pluriculturalisme des pays francophones; la dimension orale en tant que lieu privilégié de rencontres des dynamiques linguistiques, culturelles et identitaires en jeu; le rôle de l'institution scolaire dans la diffusion de la norme de référence. Molinari choisit de prendre en considération les cas particuliers du Mali, de la Martinique et du Québec, qui se différencient justement par rapport à ces facteurs. Chaque pays est examiné dans un chapitre à part, à travers la représentation littéraire (récits autobiographiques et romans) d'un auteur: Hampâté Bâ pour le Mali, Patrick Chamoiseau pour la Martinique, Michel Tremblay pour le Québec.

Le travail a deux versants. D'un côté, il présente une analyse strictement linguistique sur le langage métaphonologique des auteurs. Les enquêtes sur les techniques de transcription des sonorités sont menées d'un point de vue quantitatif et qualitatif; elles s'appuient entre autres sur les typologies verbales de Fónagy et adjectivales de Laver. 
Une attention particulière est portée aux phénomènes de langue graphiée, à savoir des fausses orthographes et d'autres moyens graphiques visant à reproduire non seulement les prononciations des personnages, mais aussi le rôle du silence dans les échanges dialogiques. En outre, les trois auteurs considérés se différencient quant à leur respect de la distinction entre séquences textuelles (narrative, dialogique, ... ) - distinction qui demeure traditionnelle dans la littérature occidentale. Cette perméabilité du récit aux voix autres que celle du narrateur, de même que la co-présence de codes linguistiques différents à l'intérieur du texte en français, semble créer autant de français «polyphonisés».

4 De l'autre côté, le travail profite d'une démarche interdisciplinaire, avec les apports de plusieurs méthodologies scientifiques. La sociolinguistique, l'écolinguistique, l'ethnographie de la communication éclairent des notions-clé relatives aux rapports de force en action, telles que marché linguistique; système "gravitationnel» linguistique; imaginaire linguistique; conflit linguistique; glottophagie; (in)sécurité formelle, statutaire, identitaire. Si tous les ouvrages examinés sont axés sur les problématiques du plurilinguisme, il devient de plus en plus apparent qu'un des enjeux primaires de l'écriture est justement la hiérarchie socio-culturelle où entrent les codes linguistiques présents dans l'univers communicatif et par conséquent la dimension identitaire des locuteurs.

5 La réflexion s'articule autour de trois hypothèses, qui sont vérifiées au cours de l'analyse. La première hypothèse est qu'il existe une relation entre la proximité ou l'éloignement des langues du pays et la manière dont le plurilinguisme diglossique est vécu. Molinari parvient à montrer que plus on passe d'un système linguistique où les composantes sont très distantes (comme au Mali) à un système où elles sont très proches (comme au Québec), plus la confrontation entre ces variétés se fait dramatique. La deuxième hypothèse concerne un lien possible entre la présence ou l'absence de dispositifs de médiation avec les situations d'éloignement ou de proximité linguistique. L'effacement des figures médiatrices semble, en effet, entrainé par le rapprochement des variétés linguistiques, mais entraîne à son tour une intensification des phénomènes d'insécurité. La troisième hypothèse est qu'il existe une relation entre les choix stratégiques effectués sur le plan de l'écriture et les conditions de sécurité ou insécurité ethniques et identitaires. Ici l'analyse aboutit, nous semble-t-il, à trois définitions récapitulatives forgées pour décrire l'univers discursif et poétique des auteurs: Molinari parle ainsi d'une «harmonie fusionnée et homogène» chez Hampâté Bâ, qui compose un portrait pacifique de la dimension plurilingue malienne; d'une «harmonie intégratrice» chez Patrick Chamoiseau, qui travaille pour récréer, avec l'identité créole, une langue rabelaisienne capable de l'exprimer en accueillant tous les apports linguistiques de la créolité; d'une «polyphonie éclatée» chez Michel Tremblay, le seul pour lequel les rapports interlinguistiques restent dramatiquement irrésolus.

6 La langue française hexagonale semble donc se présenter comme un formidable élément d'ambiguïté pour les écrivains francophones: si elle permet de traduire et de transmettre un univers linguistique et culturel, elle se pose en même temps comme un terme de confrontation parfois douloureuse. 